\title{
Thickness Measurement of Blast Furnace Staves with Curved Cooling Channel Using a Specially Designed Ultrasonic Probe
}

\author{
Shunmugasundaram RAJENDRAN, ${ }^{*}$ Shivanandan Shashidhar INDIMATH, Balamurugan SRINIWASAGAN, \\ Monojit DUTTA, Radha Raman ABHYUDAY, Gaurav TIWARI, Mantu PATRA and Uttam SINGH
}

Tata Steel Ltd., Jamshedpur-831001 India.

(Received on November 30, 2015; accepted on April 1, 2016)

\begin{abstract}
Blast furnaces in steel industries employ staves, which provide cooling to the furnace shell for maintaining structural integrity. Motion of the raw material within the furnace during operation causes the cooling staves to wear. Thickness of the staves needs to be monitored on a regular basis to avoid catastrophic failure. The staves of the furnace in question have a curved cylindrical cooling channel as opposed to straight cooling channels; which makes the thickness measurement particularly challenging in this case due to mode conversion. Ultrasonic based thickness measurement is a widely used technique in industries for stave thickness measurement. This text describes a unique modification in a conventional ultrasonic probe to measure the thickness of the staves with curved cooling channels. The modified probe is designed to avoid mode conversion due to incidence of ultrasound at oblique angles. FEM simulations were done to validate the effectiveness of the shoe followed by trials in actual furnace.
\end{abstract}

KEY WORDS: stave thickness measurement; ultrasonic testing; blast furnace; curved cooling channel and elimination of mode conversion.

\section{Introduction}

Blast furnaces are the heart of any integrated steel plant. In blast furnaces smelting of iron from iron ores is accomplished by means of various chemical reactions between the iron ore, coke and fluxes. High temperature and hot blast creates an atmosphere conducive for the chemical reactions as the charged raw materials move in the downward direction. Liquid metal is tapped from the bottom of the blast furnace. The outer shell of the blast furnace serves to isolate the reactions inside the furnace from the atmosphere in addition to providing mechanical support to the furnace. The shell generally has a multi layered structure consisting of an outer steel shell, followed by layers of refractory, cooling staves, followed by an innermost refractory lining as show in Fig. 1. This multi layered structure aids in containing heat within the furnace for maximum efficiency and the cooling staves keep the outer shell from overheating which may compromise the stability of the structure of the furnace. ${ }^{1)}$

The staves are metallic (either copper or steel) plates with embedded cooling channels for circulating cooling water which helps in efficient heat extraction at the furnace wall. Efficient heat extraction is essential in maintaining an accretion layer at the inner surface of the furnace shell for prolonging campaign life of the furnace. $\left.{ }^{2}\right)$ The staves are designed with ribs towards the inner side of the furnace at regular spacing as shown in Fig. 1. The ribs serve as fins for better heat extraction and also provide slots to hold the

* Corresponding author: E-mail: rs.sundaram@tatasteel.com DOI: http://dx.doi.org/10.2355/isijinternational.ISIJINT-2015-678 inner-most lining of refractory bricks. During the course of operation of the furnace, raw-material move in the downward direction; resulting in wear of the inner refractory lining. Continuous wear will subsequently subject the rib portion of the staves to wear. Excessive wear of the staves may lead to massive water ingression, which has the potential of causing catastrophic failure of the furnace. ${ }^{1)}$ Therefore it is vital to regularly assess the remnant thickness of the staves to preempt such a condition. As the staves are located inside the blast furnace shell (Fig. 1), thickness measurement is a challenge with respect to accessibility and

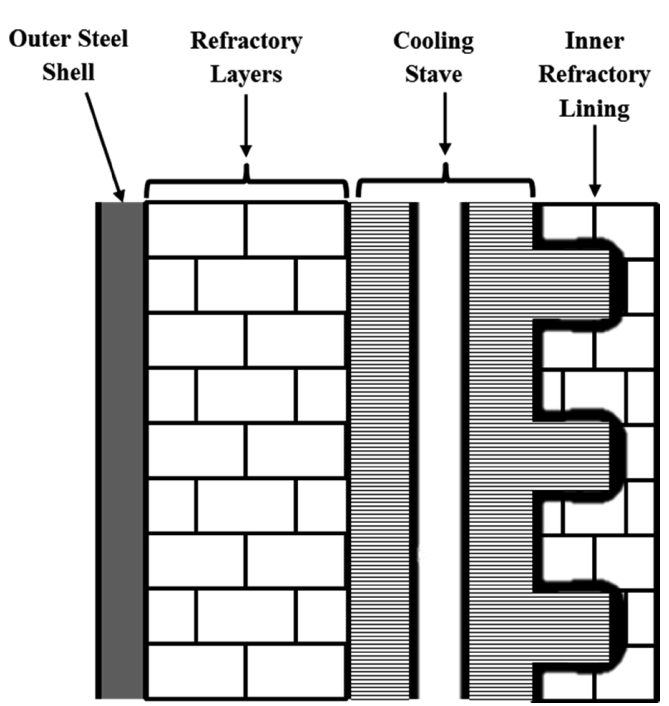

Fig. 1. Cross-section of a typical blast furnace wall. 
intricacy in the design of the cooling channel. Ultrasonic based thickness measurement techniques are thus tailored as per stave design via cooling pipes. ${ }^{3)}$

Most modern furnaces utilize cooling staves made of copper. This choice is attributed to the higher thermal conductivity of copper resulting in efficient heat extraction. Copper staves are manufactured from rolled copper bars with the cooling channels machined into them and the inlet and outlet pipes are welded with copper staves such that they intersect with the straight cooling channels as shown in Fig. 2. This makes the thickness measurement fairly straight forward by the use of conventional ultrasonic probes. ${ }^{3,4)}$ Before the advent of copper staves in blast furnaces, cast steel and cast iron staves were used widely. In cast steel and cast iron staves, the cooling channels are embedded into the staves during casting in the form of a continuous channel curved at the inlet and outlet as shown in Fig. 3. The region which is accessible for ultrasonic testing through inlet/outlet of cooling channel is inclined with respect to the rib wall as shown in Fig. 3.Thus the design of the cooling channel does not allow the use of conventional normal beam/TR probes for thickness measurement.

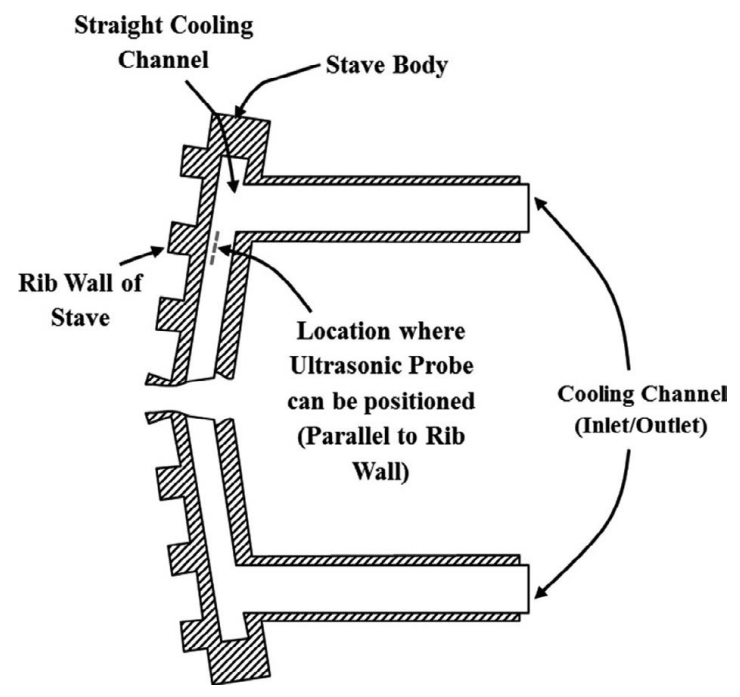

Fig. 2. Cross-section of copper stave with straight cooling channel.

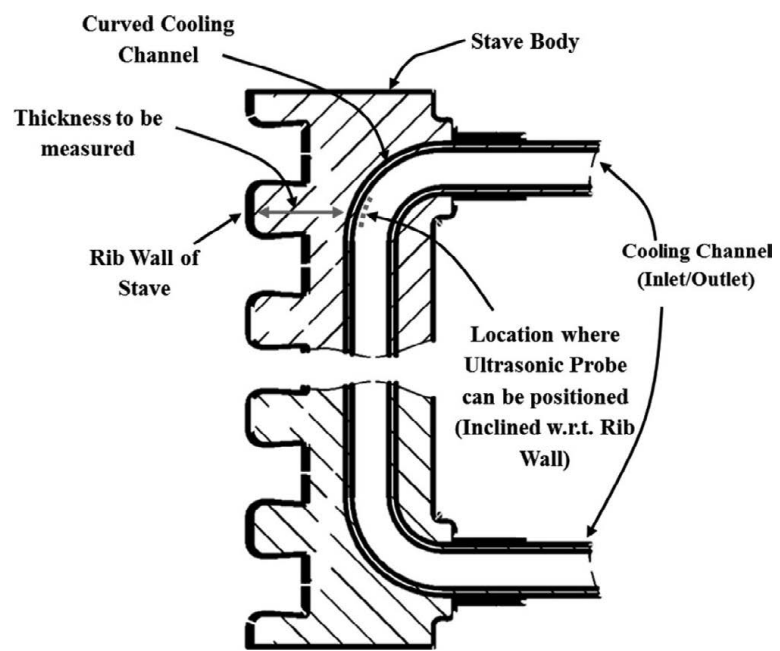

Fig. 3. Cast steel stave with curved cooling channel.

\section{The Approach}

There may be two possible approaches for generating an ultrasonic beam for measuring the thickness of the rib portion of the cooling stave at hand:

a) Approaching the rib at a location of stave where the cooling channel is not curved.

b) Using a probe with an angle of incidence such that it generates either longitudinal/shear beam in the direction perpendicular to rib wall at the bent portion of the cooling channel.

The first approach seems to be most intuitive; however positioning a probe at the location where cooling channel is not curved is a serious challenge as such a location is significantly deep inside the cooling channel. This solution is therefore not implementable.

The second approach is more practical, wherein we make a special angle beam probe such that after refraction in the cast steel stave either the longitudinal or shear wave propagates in the rib portion of the stave. It must be noted that Perspex $^{\circledR}$ is used as the material of construction for delay line in angle beam probes. Also, the stave is made of cast steel which is known to strongly attenuate shear waves. $\left.{ }^{5}\right)$ Thus longitudinal waves must be utilized for thickness measurement of rib portion as the sound needs to travel upto 150 $\mathrm{mm}$ in the cast steel stave. From Snell's law, we can easily calculate the angle of the crystal:

$$
\frac{\sin i}{\sin r}=\frac{V_{1}}{V_{2}}
$$

Where, $i$ is the angle of the crystal in the probe, $r$ is the angle of the refracted longitudinal wave in the cast steel stave, $V_{1}$ and $V_{2}$ are velocity of longitudinal wave in Perspex $^{\circledR}$ and cast steel respectively.

At the location of the cooling channel directly accessible from the inlet/outlet pipes as shown in Fig. 3, we can evaluate geometrically the angle of refracted beam as shown in Fig. 4. This angle works out to be approx. $23^{\circ}$. Using this value for $\mathrm{r}, V_{1}=2730 \mathrm{~m} / \mathrm{s}$ and $V_{2}=5900 \mathrm{~m} / \mathrm{s}$ in (1) we get $\mathrm{i}=10.42^{\circ}$.

A 2-D finite element model was made to study the propagation of ultrasound in the stave for thickness measurement using ABAQUS ${ }^{\circledR}$ Explicit FE package. Tetragonal mesh elements with an average element size of $0.25 \mathrm{~mm}$ were used for the FE model. The model consists of the portion of the stave which has the rib section at the bent cooling

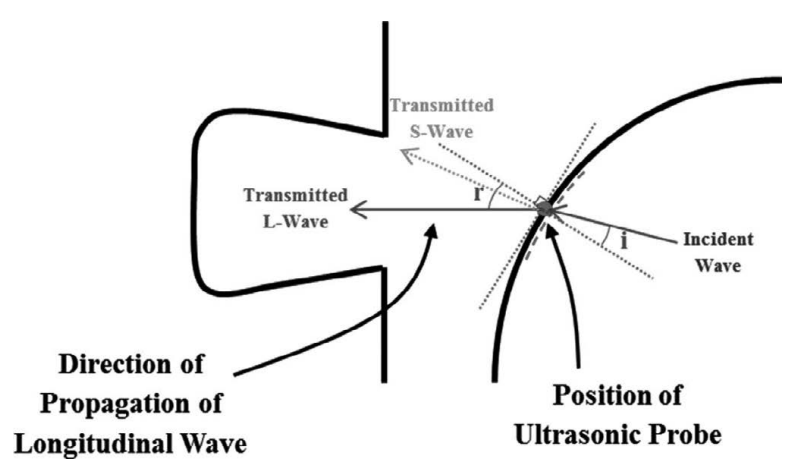

Fig. 4. Evaluation of angle of refracted longitudinal beam in the cast steel staves. 
channel with an ultrasonic probe having anangle of incidence $10.42^{\circ}$ as shown in Fig. 5. The angle of incidence was chosen as discussed above so as to generate longitudinal wave propagating horizontally for the position of the probe, which aligns with the rib. FEA revealed that although the refracted longitudinal wave propagated in the intended direction, the refracted shear wave propagated near one of the corners of the rib as depicted in Fig. 4. Actual wave propagation from FEA is shown in Fig. 5. These hear wave reflected from the corner interferes with the longitudinal wave reflected from the back-wall of the rib. This effect is due to the corners of the ribs being located at almost half the distance compared to the back-wall of ribs and the fact that the shear waves travel at approximately half the velocity of longitudinal waves. The received pulse was thus a mixture of the intended reflected longitudinal wave as well as the un-intended reflected shear wave; ultimately making the received pulse ambiguous. Figure 6 shows the A-Scan result of the simulation. From the result it is observed that the back wall echo is broad and weak due to interference of the two modes due to which signal to noise ratio (SNR) is very poor making the measurement ambiguous.

\section{Design of Probe-Shoe and Fixture}

\subsection{Design of Probe Shoe}

The root cause for the ambiguity in the signal above is primarily due to mode conversion when ultrasound is transmitted from the probe into the cast steel stave. It is known that for mode conversion to occur, following two conditions

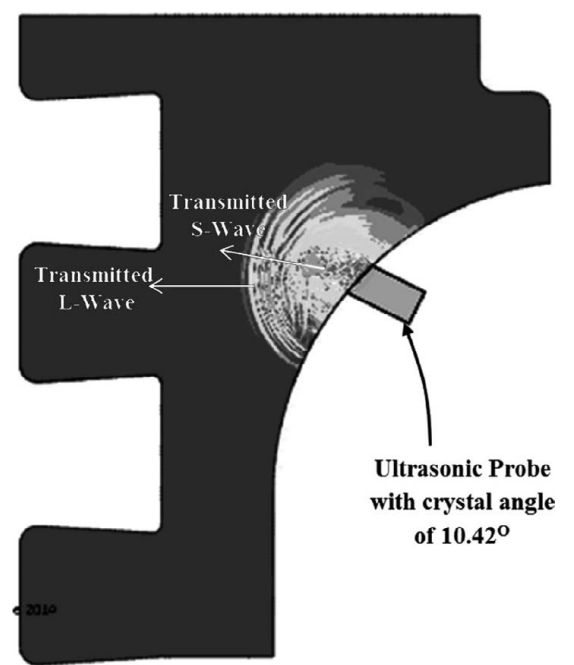

Fig. 5. FEM wave propagation.

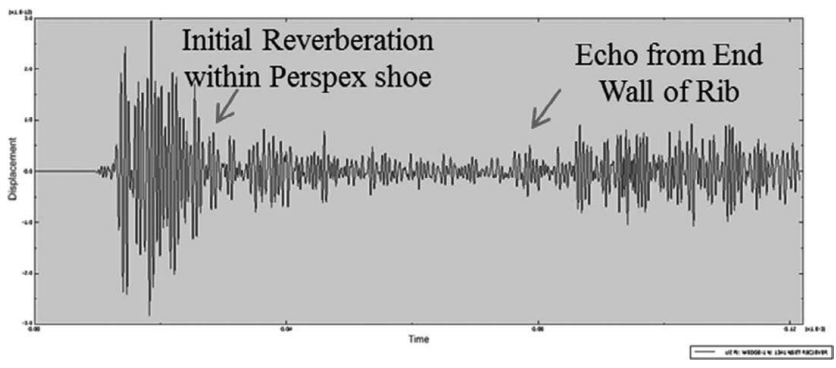

Fig. 6. Simulated A-Scan of stave thickness measurement using conventional ultrasonic probes. must co-exist:

a) Ultrasound must propagate between two media with different acoustic impedances.

b) Ultrasound must be incident at an angle other than normal at the interface between the two media.

If mode conversion is avoided, the signal will no longer be ambiguous. However, since the profile of the cooling channel at the particular location is curved; the incident angle can never be normal for transmitting the beam in the desired directionfor measuring rib thickness. Also, probes cannot be manufactured with a cast steel backing element as it will disrupt the piezoelectric circuit of the probe. Thus it is not possible to eliminate any of the above two conditions for avoiding mode conversion.

This problem was solved by separating the two conditions such that each occurs at different locations individually. This was achieved by utilizing a shoe with a flat face parallel to the rib back-wall providing a seat to place the probe (Region 1 in inset of Fig. 7) and the opposite face matching the profile of the cooling channel (Region 2 in inset of Fig. 7). Thus as the ultrasonic pulse from the normal beam probe is transmitted into the cast steel shoe, there is no mode conversion as the angle of incidence is normal at the interface. Again as this beam is transmitted from the shoe and into the stave, there is no mode conversion as both the shoe and stave are of same material, although ultrasound is incident at an oblique angle. The net effect is that an ultrasonic beam is produced in the desired direction without mode conversion.

However, multiple reflections of ultrasound within the cast steel shoe will be produced when using a single crystal probe. These multiple reflections will interfere with the intended back-wall echo making the signal ambiguous. Thus, the shoes were further modified to be used with two single crystal probes working as a Transmitter-Receiver (TR) pair. The shoes of each of these probes were acoustically isolated to prevent any cross-talk between them. Figure 8 shows the final design of the shoe operating in the TR configuration. There is one trade off however due

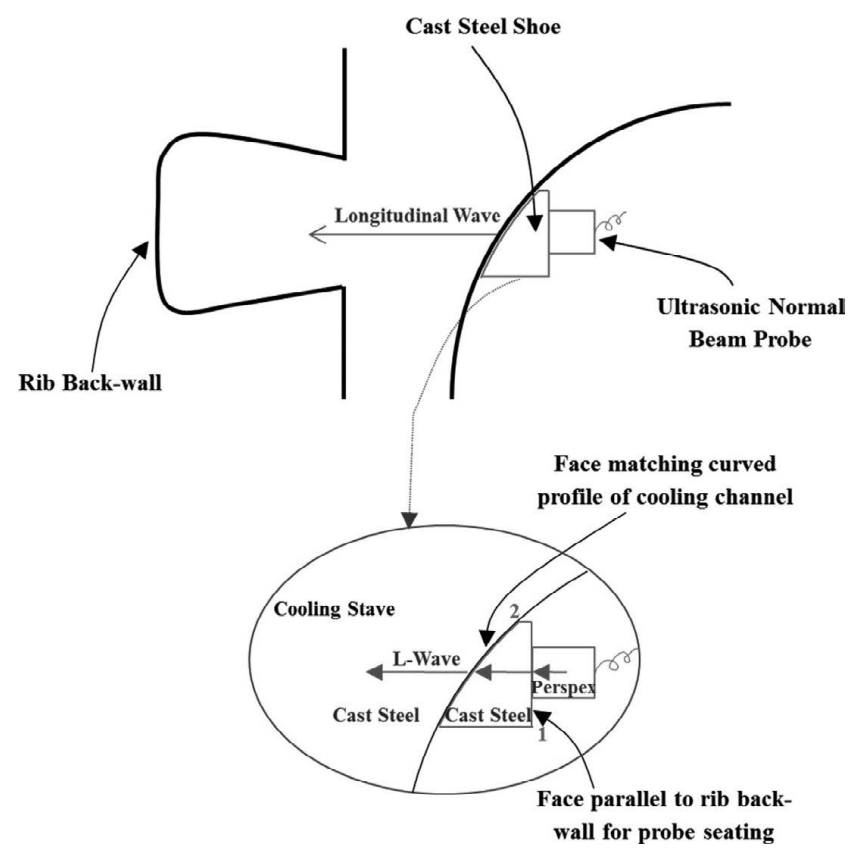

Fig. 7. Probe avoiding mode conversion using cast steel shoe. 
to the use of a cast steel shoe that the transmission losses are significantly high and thus the probes must be operated at high input voltages and receivers with high gain. Ultrasonic wave penetration increases with decrease in wave frequency; hence it is desired to use low frequency probes. In this work, $2 \mathrm{MHz}$ ultrasonic probe with crystal diameter of $10 \mathrm{~mm}$ was used.

This design was validated for stave thickness measurement by avoiding mode conversion using a 2-D FE model using ABAQUS ${ }^{\circledR}$ Explicit FE Package. The model consisting of the cast steel stave with rib thickness of $150 \mathrm{~mm}$ and the designed shoe from Fig. 8 was used. A-Scan from the simulation results is shown in Fig. 9. The thickness $(T)$ of the rib section of the stave can be calculated by Eq. (2).

$$
V=2 T / t
$$

Where, $V=5900 \mathrm{~m} / \mathrm{s}$ (velocity of ultrasound in cast steel), $t \approx 60 \mu$ s (the time of flight of the echo from endwall of rib from the initial reverberation within cast steel shoe). The thickness of the rib was calculated to be $\approx 177$ mm, using Eq. (2) and $t \approx 60 \mu \mathrm{s}$. This calculated thickness includes the average thickness of the probe shoe.

\subsection{Design of Fixture}

The designed probe has to be positioned accurately at the desired location within the cooling channel during measurement in the actual staves. This is the purpose of the fixture which carries the probe through the inlet/outlet pipe and positions it exactly at the location where stave thickness has to be measured. Height of the fixture (h in Fig. 10) is designed to align the probe with rib section. This is critical as the profile of the probe shoe will match that of the cooling channel only at this location. If the probe is positioned

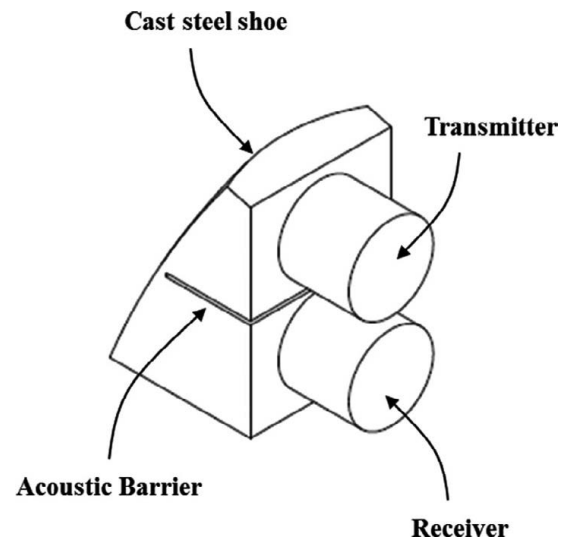

Fig. 8. Final probe and shoe assembly operating in TR configuration.

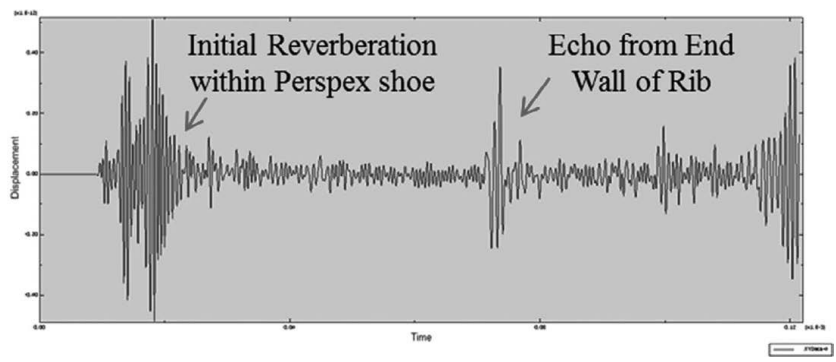

Fig. 9. Simulated A-Scan of the designed shoe with the cast steel stave. incorrectly, the probe shoe will not make proper contact with the wall of cooling channel thereby making the measurement impossible. The fixture design was adapted from ${ }^{3)}$ and suitably modified to suit the design of the staves being tested. The fixture and probe shoe are designed according to the stave design to make measurement in the rib section. Any deviation in the actual stave from the drawing will make the measurement erroneous. In some cases, such design deviations may result in the measurement being made at the thin section of the stave rather than the intended rib section. Hence, care should be taken to avoid misinterpretation of measurement due to such design deviations. The fixture was machined to be semicircular at the base such that is matches with the inner diameter of the inlet/outlet of cooling channel. The fixture is positioning the probe is depicted in Fig. 10.

\section{Measurement Results}

\subsection{Calibration of Probe}

Any measurement is meaningless unless it is calibrated with known standard values prior to the measurement of unknown values. This is also true for all ultrasonic measurements and thus the designed probe has to be calibrated with known thicknesses before accurately measuring the stave thickness in actual blast furnace. It is for this purpose, calibration blocks with the exact surface profile of the cooling channel and with known thicknesses were made. Six calibration blocks with thicknesses of $20 \mathrm{~mm}, 40 \mathrm{~mm}, 75$ $\mathrm{mm}, 115 \mathrm{~mm}, 145 \mathrm{~mm}$ and $160 \mathrm{~mm}$ were made as shown in Fig. 11. Calibration blocks are made of cast steel so as to represent the cast steel staves, whose acoustic properties are given above. Photograph of one of the blocks is shown

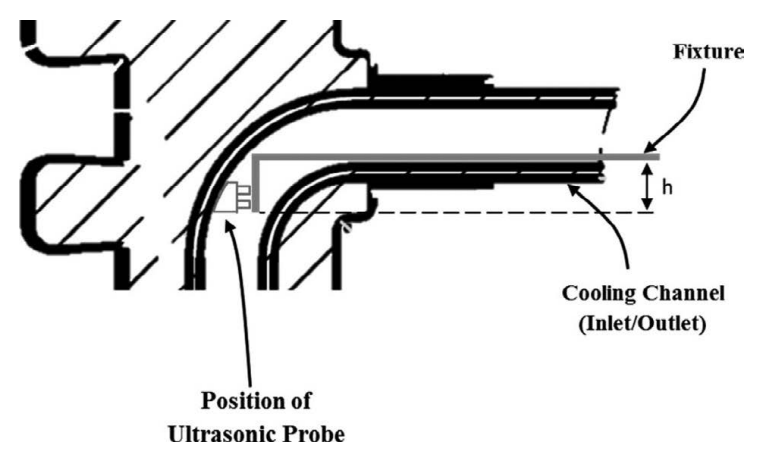

Fig. 10. Schematic of fixture: positioning the probe in cooling channel of stave.

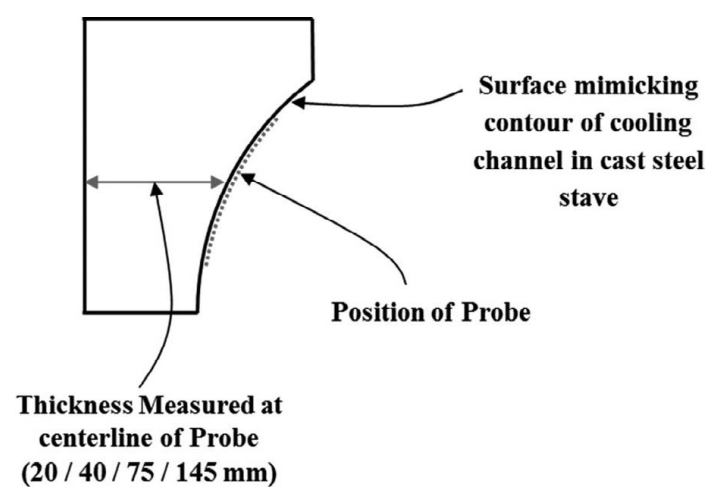

Fig. 11. Design of calibration block. 


\section{in Fig. 12.}

Ultrasonic thickness measurement of calibration blocks was done using ultrasonic flaw detector (Make: GE, Model: USM GO) and the calibration results of the probe with the designed calibration blocks are shown in Table 1. A-Scan from one of the calibrations for a block with $160 \mathrm{~mm}$ thickness is shown in Fig. 13. It should be noted that an additional delay would exist in the ultrasonic A-scans due to ultrasonic propagation in the probe shoe. The last column of Table 1 shows the effect of the shoe which causes a delay in the time of flight of ultrasound. Ideally this delay should be a constant value. However, the change in this value is attributed to the measurement error. Thus a mean of values in the last column of Table 1 can be taken as the correction factor for the designed shoe, which works out to be 22.7 $\mathrm{mm}$. This correction factor will need to be incorporated in all thickness readings by subtracting the delay due to shoe

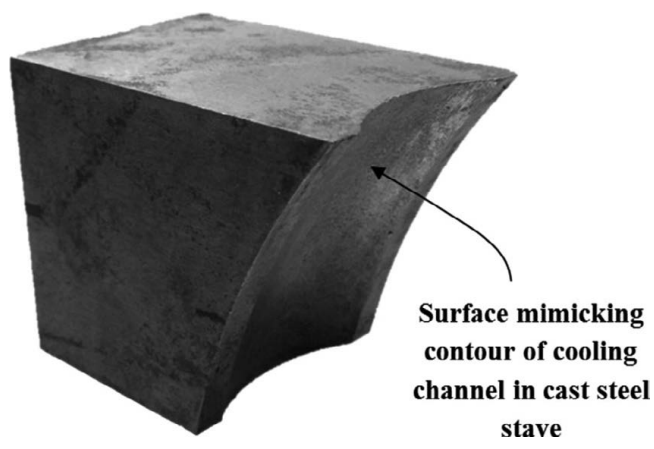

Fig. 12. Photograph of calibration block with $40 \mathrm{~mm}$ thickness.

Table 1. Calibration results of the developed probe.

\begin{tabular}{ccc}
\hline $\begin{array}{c}\text { Design Thickness of } \\
\text { Calibration Block (A) }(\mathrm{mm})\end{array}$ & $\begin{array}{c}\text { Measured Thickness } \\
(\mathrm{B})(\mathrm{mm})\end{array}$ & $\begin{array}{c}\text { Delay due to } \\
\text { shoe (B-A) (mm) }\end{array}$ \\
\hline 20 & 42 & 22 \\
40 & 64.5 & 24.5 \\
75 & 97.5 & 22.5 \\
115 & 136.6 & 21.6 \\
145 & 167.4 & 22.4 \\
160 & 183.4 & 23.4 \\
\hline
\end{tabular}

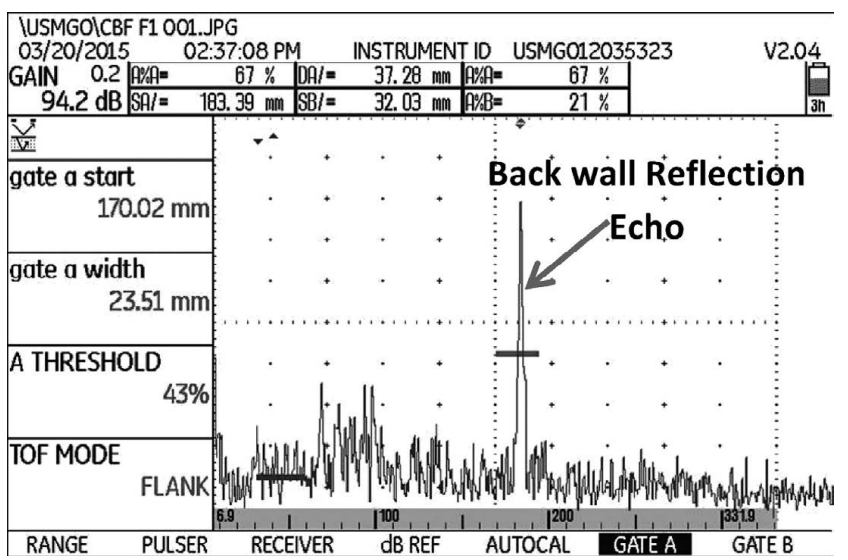

Fig. 13. Calibration A-Scan for block with $160 \mathrm{~mm}$ thickness. in order to obtain the actual thickness of the stave.

\subsection{Plant Trial}

Stave thickness measurement in actual blast furnace was carried out using the developed probe and fixture assembly. Stave thickness measurement was carried out for staves arranged in the belly section of the furnace. The cooling water was drained from the cooling channel during the testing as shown in Fig. 14. The fixture-probe assembly was inserted through the cooling pipe inlet for the measurement. The ultrasonic signal obtained is shown in Fig. 15. It can be seen that a sharp echo is obtained at $83.24 \mathrm{~mm}$. Absolute value of stave thickness is obtained by subtracting $22.7 \mathrm{~mm}$ for delay due to the shoe as discussed previously. Thickness measurement was carried out for four numbers of staves located in the same stage and the measurement results are presented in Table 2 .

Average remnant stave thickness as per the measurement result is $62.3 \mathrm{~mm}$, which is close to the thickness of the thin section of the stave. So it is inferred from the results that the readings are measured from the thin section of the staves rather than the thick section of the stave. This is due

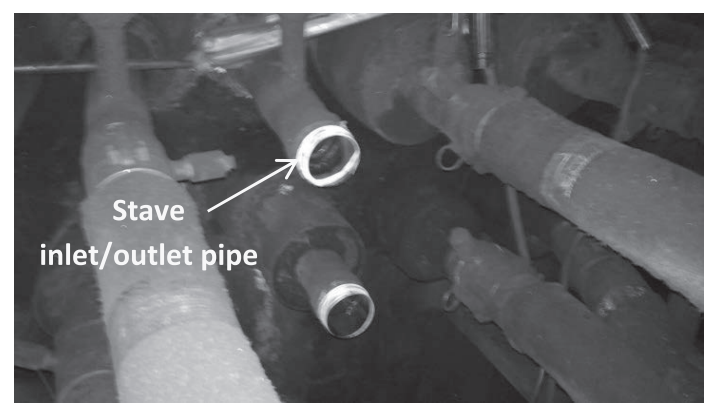

Fig. 14. Inlet/outlet pipes of stave opened for thickness measurement in blast furnace.

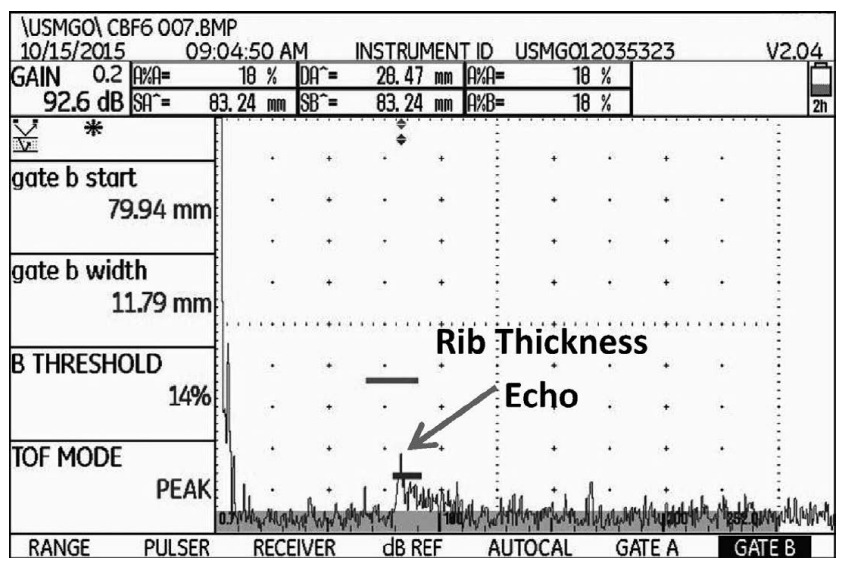

Fig. 15. Ultrasonic A-Scan of stave thickness measurement in blast furnace.

Table 2. Results of plant trial.

\begin{tabular}{ccc}
\hline S. No. & $\begin{array}{c}\text { Design Thickness of Stave } \\
\text { Thin Section }(\mathrm{mm})\end{array}$ & $\begin{array}{c}\text { Measured Stave } \\
\text { Thickness }(\mathrm{mm})\end{array}$ \\
\hline 1 & 70 & 60.54 \\
2 & 70 & 65.98 \\
3 & 70 & 61.39
\end{tabular}


to design deviation in staves with respect to rib position. Hence the fixture shown in Fig. 10 was modified with the height of " $h+\Delta h$ ", where $\Delta h$ of $20 \mathrm{~mm}$ is added to move the ultrasonic sensor head down from the earlier position. The value of $\Delta h$ is selected purely based on trial and error method, but the overall height $(h+\Delta h)$ of the fixture should not be greater than the diameter of the pipe so as to insert the fixture through the pipe. The curvature of the probeshoe also modified to match the stave curvature at the new position. At the same time another observation is that the amplitude of the plant trial signal of $62.3 \mathrm{~mm}$ (Fig. 15) is found to be less than the signal obtained for $160 \mathrm{~mm}$ thick calibration block (Fig. 13). This reduction in signal amplitude may be attributed to the roughness of cooling channel of the stave, which causes poor acoustic coupling of probe with test surface. So considering these losses, high energy/ voltage ultrasonic equipment (EPOCH\#4 model from GE was used), which can enable high penetration of sound, was used along with the modified fixture for the next trial

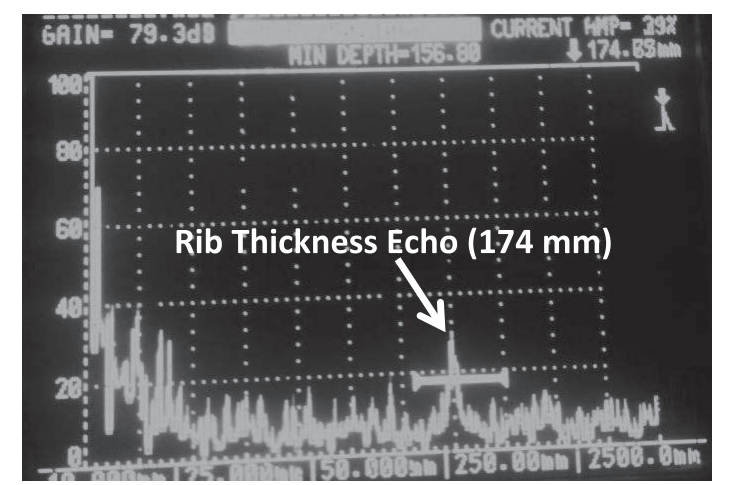

Fig. 16. Ultrasonic stave thickness measurement results with modified fixture.

Table 3. Results of plant trial with modified fixture.

\begin{tabular}{ccc}
\hline S. No. & $\begin{array}{c}\text { Design Thickness of Stave Rib } \\
\text { Section }(\mathrm{mm})\end{array}$ & $\begin{array}{c}\text { Measured Stave } \\
\text { Thickness }(\mathrm{mm})\end{array}$ \\
\hline 1 & 150 & 151.9 \\
2 & 150 & 152.3 \\
3 & 150 & 160.3 \\
\hline
\end{tabular}

of measuring the thickness of the rib section.

Next trial for measuring the thickness of the stave rib section was done by inserting the modified fixture through the cooling channel as shown in Fig. 14. The ultrasonic signal obtained from the measurement is shown in Fig. 16. As expected a sharp echo is observed at $174 \mathrm{~mm}$, which includes the shoe delay $(22.7 \mathrm{~mm})$ also. During the trial the measurement was taken from three locations (different staves) and the absolute values of stave thickness after deducting the shoe delay is given in Table 3. As per the measurement the average stave rib thickness is $154.8 \mathrm{~mm}$, which implies that the stave thicknesses at the measured locations are intact. Thus the developed probe-fixture assembly is found to be capable of assessing thickness of staves with curved cooling channels. The developed technique can be employed in every shutdown for monitoring the remnant thicknesses of the staves for the safe operation of the furnace.

\section{Conclusion}

Technique for thickness measurement of staves with curved cooling channel has been developed and discussed in detail. The additional challenge in staves with curved cooling channel is due to mode conversion of ultrasound when it is introduced into the stave. Cast steel shoe was designed in a way that the phenomenon of mode conversion was eliminated to avoid ambiguity in measurement. The design of the probe was validated with FE simulations. The modified ultrasonic probe was calibrated with calibration blocks of different thicknesses in lab scale and also the measurements were made in staves of actual blast furnace.

\section{REFERENCES}

1) K. Kawaoka, K. Anan, A. Tsuda, K. Kakiuchi, Y. Matsuo and H. Takeshita: Shinnittetsu Giho, 384 (2006), 115.

2) S.-s. Cheng, L. Qian and H.-b. Zhao: J. Iron Steel Res. Int., 14 (2007), 1 .

3) S. Balamurugan, R. Shunmugasundaram, M. Patra, S. Pani and M. Dutta: ISIJ Int., 55 (2015), 605.

4) S-W. Choi and D. Kim: AIP Conf. Proc., Vol. 31, American Institute of Physics, USA, (2012), 1715.

5) P. Ramuhalli, R. V. Harris, M. S. Good, L. J. Bond, R. Mathews and K. C. Roberts: Proc. 8th Int. Conf. NDE in Relation to Structural Integrity for Nuclear and Pressurised Components, European Commission, Joint Research Centre, Brussels, (2010), 1036. 